Artigo de Revisão

\title{
Estruturantes da base de conhecimentos para o ensino de estudantes- professores de Educação Física
}

\author{
Daniel Marcon ${ }^{1}$ \\ Amândio Braga dos Santos Graça² \\ Juarez Vieira do Nascimento ${ }^{3}$ \\ ${ }^{1}$ Curso de Educação Física da Universidade de Caxias do Sul, RS, Brasil \\ ${ }^{2}$ Faculdade de Desporto, Universidade do Porto, Porto, Portugal \\ ${ }^{3}$ Departamento de Educação Física, Centro de Desportos da Universidade Federal de Santa \\ Catarina, Florianópolis, SC, Brasil
}

\begin{abstract}
Resumo: A base de conhecimentos necessários para a atuação docente contempla o conhecimento pedagógico do conteúdo, que tem como função primordial integrar os conhecimentos dos alunos, do conteúdo, pedagógico geral e do contexto, visando à transformação dos conhecimentos do conteúdo em conhecimentos ensináveis e compreensíveis pelos alunos. Diante disso, o objetivo deste ensaio foi analisar os possíveis elementos que auxiliam na estruturação da base de conhecimentos dos futuros professores de Educação Física. A literatura consultada destaca a influência da história e todas as experiências de vida dos estudantes-professores, bem como do contexto de formação inicial, nomeadamente os professoresformadores, os colegas, as diferentes estratégias formativas, a aproximação com a realidade da profissão, e as experiências práticas, tanto as esportivas quanto as pedagógicas. A interação de todos esses elementos dá origem à estrutura da base de conhecimentos para o ensino e ao constructo do conhecimento pedagógico do conteúdo do estudante-professor.
\end{abstract}

Palavras-chave: Formação inicial de professores. Conhecimentos docentes. Conhecimento pedagógico do conteúdo.

\section{Structuring the knowledge base for teaching of preservice teachers of Physical Education}

\begin{abstract}
The knowledge base for teaching has all the knowledge needed for teaching activities, among them the pedagogical content knowledge, which main function is to integrate knowledge of students, content knowledge, pedagogical knowledge, and knowledge of context, intended to transform content knowledge to teachable and understandable knowledge to students. Given this, the aim of this paper was to analyze the possible determining factors in the structuring of the knowledge base of future teachers of Physical Education. In this sense, the literature emphasizes the influence (1) the history and all of the preservice teachers life experiences, and (2) the teacher education context, including teacher educators, colleagues, different training strategies, the approach to the reality of the profession, and practical experience, both sports as the educational. The interaction of all these elements gives rise to structure the knowledge base for teaching, and to construct the pedagogical content knowledge of preservice teacher.
\end{abstract}

Keywords: Initial teacher training. Teacher's knowledge. Pedagogical content knowledge.

\section{Introdução}

A abordagem da literatura a respeito da base de conhecimentos para o ensino leva a concebêla como a responsável por reunir todos os conhecimentos que os estudantes-professores, futuros professores, constroem sobre docência, educação, escola, aluno, professor, ensino, aprendizagem e tantos outros que dizem respeito à profissão docente e à atuação do professor. (GRACA, 1997; MIZUKAMI, 2004; SHULMAN, 1987).

A abrangência da base de conhecimentos para o ensino dos estudantes-professores foi destacada por Shulman (1987) que, ao apresentá-la, dividiu-a em sete grupos de conhecimentos, nomeadamente (1) do conteúdo,
(2) pedagógico geral, (3) do currículo, (4) dos estudantes e de suas características, (5) do contexto educacional, (6) dos fins, propósitos e valores educacionais, e (7) pedagógico do conteúdo. Dentre os integrantes da base de conhecimentos, o conhecimento pedagógico do conteúdo é o que se destaca por seu papel de integrar os demais conhecimentos visando tornar os conhecimentos do conteúdo compreensíveis e ensináveis, proporcionando a aprendizagem dos alunos. (GRACA, 1997; PARK; OLIVER, 2008; SHULMAN, 1987).

Apesar do investimento de vários autores em pesquisas relacionadas com a base de conhecimentos para o ensino, e do aparente avanço nas discussões a seu respeito, fazer 
afirmações definitivas quanto à sua composição, estrutura e condicionantes continua sendo uma aventura por caminhos sinuosos. (GRACA, 1997; JENKINS; VEAL, 2002; SEGALL, 2004; SHULMAN, 1987).

Nesse cenário, o objetivo deste ensaio foi elaborar uma breve sistematização das reflexões sobre as possíveis origens de alguns dos conhecimentos que integram a base de conhecimentos para o ensino e que têm potencial para influenciar as opções metodológicas dos futuros professores de Educação Física. Muitos desses conhecimentos, por terem participação incisiva, e em alguns casos determinante, na formação dos valores e da personalidade dos futuros professores, podem se refletir no seu conhecimento pedagógico do conteúdo e, consequentemente, na sua personalidade docente e profissional. Para analisar essas questões, procurou-se estabelecer um paralelo entre as experiências formativas anteriores e do período de formação inicial em Educação Física com a base de conhecimentos para o ensino dos futuros professores.

\section{Experiências de vida - vivências anteriores à formação inicial}

Ao ingressar na formação inicial o estudante traz consigo uma bagagem de experiências e de conhecimentos que estão enraizados na sua realidade de vida e que esculpiram, aos poucos, sua personalidade. (ROSA; RAMOS, 2008; SILVA, 2008; TARDIF; RAYMOND, 2000). Esses fatores influenciam o modo de ser do estudante, a maneira como interpreta as diferentes situações à sua volta e suas concepções sobre o contexto em que está inserido, e são manifestados em suas ações e em seu posicionamento diante da realidade. (GARCIA, 2001; LIMA; REALI, 2002; ROSA; RAMOS, 2008).

Essa bagagem de experiências e de conhecimentos tem origem em diferentes instâncias da vida do estudante. Além de contemplar três grandes contextos: familiar, escolar e extraescolar (CAPEL, 2007; PERDIGÃO, 2002; TARDIF; RAYMOND, 2000), é utilizada, inclusive, para orientar a análise da relação entre os estudantes e a Educação Física.

No contexto familiar, no convívio com pais, irmãos e parentes, se espera que a criança aprenda a respeitar as regras e a hierarquia familiar; a importância de dividir e de compartilhar; a necessidade de respeitar o próximo para um convívio social harmônico e fraterno; e a discernir entre o bem e o mal, entre o certo e o errado. Se a educação familiar estiver apoiada em princípios como esses, todos esses elementos começarão a desenvolver os sensos de responsabilidade e de justiça na criança, e influenciarão sua personalidade. Caso contrário, a formação dos valores e da personalidade da criança poderá ser afetada, refletindo, por exemplo, em sua vida pessoal, social e profissional. (FILGUEIRA; SCHWARTZ, 2007; REALI; TANCREDI, 2002).

Assim como a família, a escola também tem participação determinante na formação dos valores e da personalidade das crianças e dos adolescentes. Além dos conteúdos de cada uma das disciplinas curriculares, alguns aprendizados implícitos são oportunizados aos estudantes. (FORMOSINHO, 2001; OLIVEIRA; MIZUKAMI, 2002; TARDIF; RAYMOND, 2000). Frequentar a escola e participar da comunidade escolar por mais de uma década permite que os estudantes se tornem, juntamente com os professores, as pessoas que conhecem com mais profundidade a instituição escolar e o processo de ensino e aprendizagem. (DARIDO, 1995; LIMA; REALI, 2002; ROSA; RAMOS, 2008; TARDIF; RAYMOND, 2000).

Um aspecto a destacar é que os conhecimentos apresentam dimensões e focos diferenciados, já que os professores possuem sua própria bagagem e passaram por uma formação específica para a docência. Entretanto, o conhecimento dos estudantes sobre os aspectos constituintes $e$ as relações estabelecidas no contexto escolar é constantemente reformulado e consolidado à medida que avançam os anos e se diversificam suas experiências. (LIMA; REALI, 2002; TARDIF; RAYMOND, 2000). O resultado desse lento e marcante processo é a construção de uma interpretação personalizada sobre todos os elementos que compõem o ensino e a escola, e vai, gradativamente, deixando profundas marcas e sendo incorporado em sua personalidade. (CALDERHEAD, 1988; OLIVEIRA; MIZUKAMI, 2002; SILVA, 2008).

Com o tempo de convívio no ambiente escolar, os estudantes passam a saber, em maior ou menor medida, como se dá a relação entre professores e alunos; quais as principais 
estratégias que os professores utilizam para ensinar; qual a profundidade do conhecimento dos professores sobre os conteúdos que ensinam; como administram situações de indisciplina, dificuldades de aprendizagem, número grande de alunos e material didático insuficiente ou inadequado; como é a estrutura organizacional e hierárquica da escola; como a escola se insere na sociedade e como a sociedade participa da comunidade escolar. (DARIDO, 1995; PERDIGÃO, 2002; TARDIF; RAYMOND, 2000). Por tudo isso, ao concluírem o ensino médio os estudantes podem ser considerados "especialistas em escola", pois jamais frequentaram um contexto social por um período tão prolongado e com tantos estímulos como esse. (PERDIGÃO, 2002; TARDIF; RAYMOND, 2000).

Portanto, se pode dizer que o professor começou a ser professor quando frequentou os bancos escolares, quando fazia parte da comunidade escolar no papel de aluno. Como explica Ennis (1994), é natural que os "futuros professores tenham desenvolvido um sistema de crenças sobre o ensino durante a sua experiência como estudantes dos ensinos fundamental e médio". (p. 172, tradução nossa). No dizer de Formosinho (2001), "a docência é uma profissão que se aprende na vivência da discência. Todos os futuros professores têm no seu longo currículo discente uma aprendizagem de que emergem teorias e representações acerca do que é o ser professor". (p. 39).

É justamente nesse período que o professor começou a construir suas concepções sobre os elementos que envolvem a escola, os processos de ensinar e de aprender (BEHETS; VERGAUWEN, 2006; GROSSMAN et al., 1989; ROSA; RAMOS, 2008; SILVA, 2008) e, ao evocar qualidades desejáveis ou indesejáveis que quer encarnar ou evitar como professor, ele se lembrará da personalidade marcante de uma professora [...], de uma injustiça pessoal vivida na pré-escola ou das intermináveis equações impostas pelo professor de química no fim do [ensino médio]. (TARDIF; RAYMOND, 2000, p. $\underline{216})$.

A participação das relações sociais extraescolares também incide na bagagem de experiências e de conhecimentos dos estudantes, já que contribuem para a formação dos valores e da personalidade dos jovens e na maneira como interpretam e se inserem na sociedade. (CAPEL, 2007; FILGUEIRA; SCHWARTZ, 2007; SÁ,
2000). Tendo em vista a amplitude do tema, a grande atenção recebida de vários pesquisadores e os objetivos do presente ensaio, essas questões não serão aprofundadas neste momento.

No que tange especificamente à Educação Física, mesmo não sendo consenso na literatura, há indícios de que a família, a escola e a sociedade participem na construção das concepções dos estudantes sobre temas como saúde, estilo de vida fisicamente ativo e prática de atividades físicas e esportivas. (ENNIS, 1994; MACHADO et al., 2009; SÁ, 2000; ZANETTI et al., 2008). Em uma família onde, por exemplo, os pais praticam atividades físicas e esportivas, podem ser elevadas as chances de que as crianças tomem gosto pela prática ou se interessem por essas questões. (FILGUEIRA; SCHWARTZ, 2007). Além disso, o convívio em uma família que, apesar de não praticar tais atividades, é expectadora, admira e se envolve, por exemplo, com competições esportivas, mesmo que pela televisão, pode fomentar em seus filhos o gosto por essas atividades e, como consequência, o interesse por aquela prática

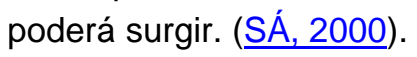

Nesse contexto, a escola também desempenha papel de destaque. Aulas motivadoras, que envolvem a todos e conferem significado e importância às estratégias propostas, têm grandes chances de favorecer 0 despertar do gosto pela prática de atividades físicas e esportivas fora da escola, o que poderia levar à sua incorporação na rotina de vida dos alunos. (DARIDO, 2004; FILGUEIRA; SCHWARTZ, 2007; VAGO, 1996).

A participação da sociedade na decisão dos jovens por praticar ou não atividades físicas e esportivas pode se dar basicamente de duas maneiras. Os círculos de amizade influenciam os jovens ao ponto de fazê-los optar, em maior ou menor medida, pela prática de uma modalidade ou de outra, por uma frequência maior ou menor, com objetivos competitivos ou de lazer, ou, simplesmente, por não participar. (CAPEL, 2007; MACHADO et al., 2009; SÁ, 2000; TINNING, 2002).

Além das relações de amizade, atualmente uma das influências sociais mais marcantes é da mídia, que utiliza potentes recursos para fazer com que sociedade, e, principalmente, os jovens, 
se interessem por diversas atividades físicas e modalidades esportivas. (PIRES, 2007; SÁ, 2000; VAGO, 1996). Esse interesse pode variar desde 0 simples consumo, como expectadores em suas residências ou nos locais de realização, até a decisão por também praticarem.

Ao aderir à prática, o jovem se aproxima das peculiaridades que a caracterizam, de seus aspectos físico, técnico e tático, de questões como qualidade de vida e cuidados com a saúde, relações interpessoais e de convívio em grupo. (ENNIS, 1994; VAGO, 1996). Mesmo realizada sem orientação profissional, essas informações podem ser adquiridas com colegas, na mídia e em sites sobre esportes e atividades físicas e de lazer. (PIRES, 2007; ZANETTI et al., 2008).

Entretanto, a mera aquisição de informações pode ser superada por meio da iniciação esportiva profissionalmente orientada, ampliandose os conhecimentos dos jovens sobre a modalidade, sobre os processos de ensino e aprendizagem e sobre aspectos relacionados ao convívio com os colegas, ao estilo de vida fisicamente ativo e à qualidade de vida. (ENNIS, 1994; SÁ, 2000; ZANETTI et al., 2008). Esses são, pois, alguns dos estímulos que podem influenciar os jovens no período escolar e determinar tudo que eles sabem sobre a Educação Física, a prática de atividades físicas e esportivas e, até mesmo, sobre o ensino de determinadas modalidades. (BEHETS; VERGAUWEN, 2006; COSTA; NASCIMENTO, 2009). De acordo com Ennis (1994), "a família dos alunos, seu envolvimento com a escola e com a prática esportiva federada influenciam suas percepções sobre a Educação Física". (p. 172, tradução nossa).

As diferentes instâncias de vida (família, escola e sociedade) deixam marcas tão profundas na personalidade do jovem que algumas de suas concepções não são alteradas nem mesmo sob influência do processo de formação inicial. (BEHETS; VERGAUWEN, 2006; FORMOSINHO, 2001).

Observa-se, assim, a necessidade de serem consideradas as concepções e os conhecimentos construídos ao longo da infância e do período escolar na formação inicial dos futuros professores, visto que

há muito mais continuidade do que ruptura entre o conhecimento profissional do professor e as experiências pré-profissionais, especialmente aquelas que marcam a socialização primária (família e ambiente de vida), assim como a socialização escolar enquanto aluno. (TARDIF; RAYMOND, 2000, p. 218).

Sobre esse assunto, Formosinho (2001) destaca que cabe ao programa de formação "analisar estas aprendizagens e incorporá-las nos processos formativos, de modo a (re)construir a imagem que os estudantes já têm do ofício de professor". (p. 40). Pajares (1992) comenta, também, que as

crenças são os melhores indicadores das decisões que os indivíduos tomam ao longo de suas vidas. Compreender as estruturas de crenças dos professores e futuros professores é essencial para melhorar a sua preparação profissional e suas práticas de ensino". (Apud ENNIS, 1994, p. 169, tradução nossa).

Essa preocupação se deve ao fato de que os estudantes levarão para o ensino superior sua própria compreensão sobre a escola, sobre o processo de ensino e aprendizagem, sobre a profissão de professor e sobre a própria Educação Física. (CALDERHEAD, 1988; COSTA; NASCIMENTO, 2009; DARIDO, 1995). De acordo com Formosinho (2001, p. 40),

o estudante de formação inicial tem já uma imagem consolidada do que é ser aluno e também do que é ser professor. Esta aprendizagem experencial é parte essencial da formação prática de um professor.

Todos os aspectos apresentados, além de darem pistas da estrutura inicial da base de conhecimentos, constituem alicerces que sustentarão os conhecimentos do conteúdo, os conhecimentos pedagógicos e toda a formação inicial do futuro professor, delineando gradativamente os contornos de sua personalidade docente e profissional. (REALI; TANCREDI, 2002).

Portanto, ao ingressar no ensino superior, e de posse desse repertório de conhecimentos e experiências, o jovem deixa para trás o papel de estudante assumido por mais de uma década e passa a ser considerado um estudante-professor, já que começa a direcionar sua atenção para a formação acadêmica e profissional e para a profissão que terá no futuro.

\section{Vivências do período de formação inicial}

Desde o ingresso no ensino superior, e ao longo da formação inicial, o estudante-professor será submetido a inúmeros e constantes estímulos, sejam eles advindos dos contextos universitário ou profissional, pessoal ou social, 
que o defrontarão com diferentes dilemas, instigarão a crítica e o questionamento e exigirão que se posicione e que tome decisões. Essas diversas experiências contribuirão para a ampliação e consolidação dos conhecimentos na sua base de conhecimentos para o ensino, podendo determinar, inclusive, os caminhos seguidos na sua formação docente e profissional.

No processo de formação inicial de professores, o contexto universitário será aquele que oferecerá as principais e mais marcantes oportunidades para que os conhecimentos que compõem a base de conhecimentos para 0 ensino dos estudantes-professores sejam analisados, desestabilizados, reconstruídos e ampliados. (FORMOSINHO, 2001; GRABER, 1995; SILVA, 2008).

Em dependência das concepções que sustentam o programa de formação inicial, a construção desses conhecimentos pode se dar, por exemplo, por meio de estratégias planejadas especificamente para esse fim ou não; de estudos e pesquisas bibliográficas ou das aulas dos professores-formadores; de observações, análises e debates de outras aulas ou das situações de ensino e aprendizagem ministradas por eles próprios; no contato com alunos da comunidade ou na troca de experiências com seus colegas; e na instituição de ensino superior ou na atuação profissional paralela. (COCHRAN et al., 1991; GIMENO SACRISTÁN, 1995; SHULMAN, 1987). A interação dessas experiências, além de se refletir na estrutura da base de conhecimentos dos estudantesprofessores, potencializa a incidência do programa formação sobre sua formação acadêmica e profissional.

O reconhecimento do papel dos professoresformadores é destacado nesse sistema, e se dá em função da sua responsabilidade de oportunizar aos estudantes-professores 0 ingresso gradual, orientado e consciente na profissão de professor, apresentando-lhes os inúmeros elementos constituintes, as diversas facetas que a compõe e como a inter-relação entre eles ocorre e contribui para a estruturação do perfil docente e profissional do futuro professor. (CALDERHEAD, 1988; COCHRAN et al., 1991).

Isso se verifica à medida que os estudantesprofessores pautam muitas de suas aprendizagens sobre a docência na forma como seus próprios professores atuam $\mathrm{e}$ desempenham suas funções docentes $e$, de maneira intuitiva, extraem e absorvem informações a partir do comportamento dos professores-formadores. (CALDERHEAD, 1988; TARDIF; RAYMOND, 2000). Sobre esse assunto, Formosinho (2001) comenta que,

na formação de professores esta transmissão da base de legitimidade profissional ocorre de forma indireta ou direta, ao longo de todo o curso, permitindo ao aluno confrontar a prática docente experenciada nas disciplinas com a prática docente que, de forma implícita ou explícita, os diferentes professores formadores sugerem. Essa avaliação permanente da coerência entre $o$ feito e o dito é específica da formação de professores. (p. 38).

Os estudantes-professores elaboram suas concepções, portanto, relacionando suas experiências de vida com as características que observam em seus professores-formadores, cujo resultado, além de ser enviado para a base de conhecimentos, serve de fundamento para o estabelecimento dos seus próprios parâmetros de conduta docentes e profissionais. (FORMOSINHO, 2001; GROSSMAN et al., 1989).

Assim como os professores-formadores, a comunidade acadêmica e, principalmente, as relações com os colegas, também podem influenciar 0 delineamento da base de conhecimentos para o ensino e a constituição da personalidade docente e profissional do estudante-professor. Dependendo dos conhecimentos e das concepções já trazidas em sua base de conhecimentos, o estudanteprofessor será mais seletivo com suas companhias, terá condições de julgar atitudes inadequadas e estará munido de critérios para analisar o caráter, os conhecimentos e os objetivos dos colegas. (STEFANE; MIZUKAMI, 2002). Todos esses fatores aumentarão a sensibilidade do estudante-professor para aprender com as inúmeras situações à sua volta, Ihe darão condições de selecionar exemplos positivos que deseja incorporar em sua própria personalidade e the permitirão analisar exemplos negativos como parâmetros de conduta para não serem seguidos. (TARDIF; RAYMOND, 2000).

Além das marcas que começam a ser deixadas na personalidade docente e profissional dos estudantes-professores pelos professoresformadores e pelos colegas, os novos conteúdos com os quais se deparam, bem como a 
aproximação com a comunidade e com a realidade da profissão, começam a abrir as portas da profissão e a indicar caminhos para sua carreira profissional.

Ao interagir com todo o contexto de formação inicial e com a própria estrutura curricular por meio de diferentes estratégias e conteúdos relacionados à área de atuação e à profissão de professor, o estudante-professor estabelece conexões, sejam elas naturais ou estimuladas pelos professores-formadores ou pelo próprio ambiente, que ocasionam a reestruturação dos antigos e a construção de novos conhecimentos. Todos esses conhecimentos, bem como todos os estímulos aos quais os estudantes-professores estão submetidos ao longo da formação inicial constituem elementos com grande potencial para influenciar tanto a base de conhecimentos para o ensino quanto a construção do conhecimento pedagógico do conteúdo, podendo determinar não apenas sua estrutura, mas sua abrangência e profundidade. (CALDERHEAD, 1988; GIMENO SACRISTÁN, 1995; GROSSMAN et al., 1989).

Além disso, desde os períodos mais iniciais da formação em Educação Física, o contato dos estudantes-professores com o objeto de estudo da área não se dá apenas no campo teórico e nem pelas estratégias e estímulos elencados anteriormente, mas por meio de diferentes experiências práticas. Excetuando-se aquelas relacionadas com a investigação científica, as práticas vivenciadas pelos estudantesprofessores ao longo dos programas de formação inicial em Educação Física podem ser divididas, de modo geral, em práticas esportivas e práticas pedagógicas (SIEDENTOP, 2002) ou como componente curricular (BRASIL, 2004a; BRASIL, 2004b).

Tendo em vista o tempo que os programas de formação inicial em Educação Física dedicam às experiências práticas, além do seu potencial para participar na estruturação e na consolidação da base de conhecimentos dos estudantesprofessores e, consequentemente, na construção do seu conhecimento pedagógico do conteúdo, as práticas esportivas e as práticas como componente curricular serão analisadas separadamente.

\section{Contribuições das práticas esportivas}

As práticas esportivas constituem, muito provavelmente, aquelas com as quais os estudantes-professores, oriundos do ensino médio e recém ingressantes na formação inicial, tiveram mais contato e oportunidade de vivenciar. Mesmo aqueles que não possuem uma vasta experiência com a prática de modalidades esportivas ao longo da vida podem possuir conhecimentos básicos sobre algumas delas, mesmo que sejam advindos apenas das aulas de Educação Física na escola ou, talvez, da mídia e ou de outras fontes. (DARIDO, 1995; 2004; PIRES, 2007; SÁ, 2000; VAGO, 1996).

Entretanto, aqueles estudantes-professores que são, ou que no período escolar, em que frequentavam os ensinos fundamental e médio, foram atletas, mesmo que amadores, podem possuir grande experiência com a prática de determinada modalidade e terem construído conhecimentos que não dizem respeito apenas à prática com fim em si mesma, suas regras, técnica e tática, mas conhecimentos elementares sobre estratégias de ensino e de treinamento; sobre correções, dicas, exemplos e demonstrações; sobre anatomia, fisiologia, biomecânica, treinamento esportivo e psicologia esportiva; entre tantos outros. (CALDERHEAD, 1988; ENNIS, 1994; TINNING, 2002).

As informações e os conhecimentos dessa natureza têm grande potencial para participar no delineamento da estrutura da base de conhecimentos dos estudantes-professores, conferindo a ela tanto um caráter permeável, que permite livre acesso a novos conhecimentos, quanto um caráter impermeável, que restringe o ingresso de novos conhecimentos no seu interior.

Essas questões reforçam a necessidade de serem considerados os conhecimentos prévios dos estudantes-professores como alguns dos condicionantes iniciais da estruturação da sua base de conhecimentos para o ensino. Em muitos casos, conforme analisado anteriormente, esses conhecimentos podem ser tão sólidos e consistentes ao ponto de influenciarem significativamente a interpretação e a concepção dos estudantes-professores sobre o processo de ensino e aprendizagem, determinando, inclusive, muitas de suas atitudes e decisões metodológicas. (COSTA; NASCIMENTO, 2009; FORMOSINHO, 2001; TARDIF; RAYMOND, 2000).

Mesmo assim, o que se tem observado é que os programas de ensino das disciplinas 
esportivas dos cursos de formação inicial de professores de Educação Física ratificam essas questões, à medida que têm sido constituídos, fundamentalmente, "de atividades motoras próprias do esporte, ginástica, jogos, dança e recreação, e não de conhecimentos estruturados acerca dessas atividades". (TANI, 1995, p. 21). Em razão desse enfoque demasiadamente prático, a função dessas disciplinas "tem se resumido à simples transmissão do patrimônio cultural historicamente acumulado, apoiada em experiência, intuição e senso comum do docente que as ministra". (TANI, 1995, p. 21).

Essa preocupação ganha ainda mais destaque nas primeiras disciplinas curriculares, já que muitos estudantes, recém chegados do ensino médio, trazem consigo uma concepção demasiadamente técnica e "esportivizada" dessa prática, do jogar pelo jogar, com o simples objetivo de se divertir ou de ser vitorioso. Nesses casos, a interpretação

essencialmente prática que os graduandos têm ao ingressar acaba sendo reforçada, pois as suas expectativas de ter um curso superior recheado de atividades práticas em esporte, jogos, dança e assim por diante são de fato amplamente atendidas. (TANI, 1995, p. 18).

Diante desse cenário, a prática esportiva que se espera na formação inicial em Educação Física é aquela que assume o compromisso de lapidar os conhecimentos anteriores e, a partir deles, construir e aperfeiçoar novos conhecimentos por meio da inter-relação com a base de conhecimentos, os estudos teóricos e os conhecimentos dos professores-formadores e dos colegas. (MARCON et al., 2007; NASCIMENTO et al., 2009; MIZUKAMI, 2002).

Assim, uma das metas das práticas esportivas na formação inicial passa a ser, juntamente com o aperfeiçoamento dos conhecimentos sobre as diferentes expressões e manifestações do movimento humano, a conscientização dos estudantes-professores quanto à justificativa da sua presença no programa de formação. (GARCIA, 2001; SEGALL, 2004; TANI, 1995).

O professor-formador se insere nesse contexto como o responsável por conferir esse caráter às práticas esportivas, alertando os estudantes-professores para que interpretem aquela prática como mais uma oportunidade para construírem conhecimentos sobre a modalidade e seu ensino (CALDERHEAD, 1988; GROSSMAN et al., 1989; SIEDENTOP, 2002), e que passem a analisá-la com o olhar de um professor que, dentro de algum tempo, será o responsável por ministrar uma aula sobre aquele e outros assuntos para diferentes alunos, com diferentes objetivos e em diferentes contextos. (GRACA, 2001; SEGALL, 2004; SHULMAN, 1987). Ao mesmo tempo, essa postura diante das práticas esportivas evitará uma formação alienada, exclusivamente técnica, esportivista e acrítica, cujo objetivo resume-se em saber-fazer ou, no máximo, em saber-fazer como condição para poder ensinar. (DARIDO, 1995).

Desse modo, algumas das finalidades das práticas esportivas nos programas de formação inicial de professores de Educação Física passam a ser a ampliação, a estruturação e a consolidação dos conhecimentos que compõem a base de conhecimentos dos estudantesprofessores, muitos deles relacionados especificamente com o conteúdo, para que seja possível sua posterior adaptação pedagógica. (NASCIMENTO et al., 2009). Nesse caso, os conhecimentos do conteúdo sofrerão uma transformação que, comandada pelo conhecimento pedagógico do conteúdo, os converterá em conhecimentos ensináveis, viabilizando o ensino daquela e de outras modalidades para seus alunos no futuro. (GRACA, 2001; MARCON et al., 2007; SEGALL, 2004; SHULMAN, 1987).

Essas questões ganham relevo já que os conhecimentos relacionados ao conteúdo são considerados, em alguns casos, os principais alicerces da construção do conhecimento pedagógico do conteúdo dos estudantesprofessores. (SHULMAN, 1987; SIEDENTOP, 2002; TINNING, 2002).

A prática esportiva configura, assim, uma das estratégias de formação com potencial para influenciar a estruturação da base de conhecimentos para o ensino e a construção do conhecimento pedagógico do conteúdo dos futuros professores, desde que sua presença no programa de formação inicial seja assim concebida. (MARCON et al., 2007; NASCIMENTO et al., 2009; SIEDENTOP, 2002).

Sem embargo, não se pode esperar que as práticas esportivas, por elas mesmas, sejam responsáveis pela construção de conhecimentos definitivos quando se trata do ensino da 
Educação Física. Apesar da relativa contribuição para 0 desenvolvimento da base de conhecimentos e para a construção do conhecimento pedagógico do conteúdo, a participação mais incisiva das práticas esportivas na formação docente e profissional dos futuros professores esbarra em algumas questões tradicionalmente conhecidas. Dentre elas estão, por exemplo, a inviabilidade de aperfeiçoar a prática esportiva dos estudantes-professores durante a formação inicial em virtude, principalmente, (1) do nível insuficiente das habilidades motoras prévias dos estudantesprofessores, que dificulta sua evolução satisfatória na prática das modalidades esportivas presentes na estrutura curricular; (2) do pouco tempo disponível no período de formação inicial para a realização dessas práticas, e da incoerência em investir esse tempo no aperfeiçoamento das habilidades motoras dos futuros professores; e, destacadamente, (3) dos objetivos dos programas de formação de professores não condizerem com a formação de atletas. (TANI, 1995).

Fica evidente, portanto, que a base de conhecimentos e o conhecimento pedagógico do conteúdo não se desenvolverão apenas em função da prática esportiva, pois, mesmo que o estudante-professor seja um exímio atleta, saber jogar, correr, nadar, dançar e lutar não oferece todos os conhecimentos necessários para seu ensino. (GARCIA, 2001; SIEDENTOP, 2002). Ou seja, "embora uma compreensão pessoal da matéria seja necessária, não é condição suficiente para [ser] capaz de ensinar". (MIZUKAMI, 2004, p. 5).

Esse conhecimento relacionado ao conteúdo, construído sobre e a partir da prática esportiva e de um sólido embasamento teórico, necessitará ser submetido àquele tratamento pedagógico, àquela transformação à luz dos conhecimentos pedagógicos referida anteriormente, os quais, e só então, possibilitarão ao estudante-professor ensinar aos outros aquilo que acabou de aprender para si. (GRAÇA, 2001; SEGALL, 2004; SHULMAN, 1987). Serão esses conhecimentos que começarão a distinguir 0 estudanteprofessor, do ensino superior, do estudante que era antes, na educação básica, e, principalmente, permitirão diferenciar o professor de Educação Física do atleta, já que passará a possuir uma base de conhecimentos para o ensino e um conhecimento pedagógico do conteúdo que lhe possibilitarão intervir, de maneira criteriosa, consciente e planejada, em diferentes contextos de ensino e aprendizagem. (GRAÇA, 1997, 2001; MIZUKAMI, 2004; TANI, 1995).

\section{Contribuições das práticas como componente curricular}

De acordo com as Diretrizes Curriculares Brasileiras para cursos de formação de professores, a formação inicial "deve assegurar a indissociabilidade teoria-prática por meio da prática como componente curricular", sendo contemplada no projeto pedagógico e vivenciada em diferentes contextos desde o início do curso. (BRASIL, 2004b, p. 4). Para isso, as práticas como componente curricular devem ser inseridas no "contexto programático das diferentes unidades de conhecimento constitutivas da organização curricular do curso" e "viabilizadas sob a forma de oficinas, laboratórios, entre outros tipos de organização que permitam aos(às) graduandos(as) vivenciarem $o$ nexo entre as dimensões conceituais e a aplicabilidade do conhecimento". (BRASIL, 2004a, p. 13).

Verifica-se, nesse caso, que as práticas como componente curricular, contempladas na legislação específica da formação de professores de Educação Física, dizem respeito às diferentes estratégias que o estudante-professor participa ao longo de sua formação inicial visando sua preparação pedagógica para a intervenção docente de qualidade.

A princípio, poderia se pensar que as vivências pedagógicas, às quais se referem às práticas como componente curricular, estivessem relacionadas especificamente com a prática da docência, com a participação em situações reais de ensino e aprendizagem, e nas quais o próprio estudante-professor assumisse 0 papel de professor-estudante.

Entretanto, as práticas como componente curricular também são representadas por outras estratégias de formação, como por exemplo, observações orientadas; análises de aulas ministradas por professores experientes ou pelos colegas; reflexões individuais e coletivas de diferentes práticas pedagógicas; estudos de casos de professores, aulas ou alunos; e apresentações de trabalhos sobre o processo de ensino e aprendizagem. (COCHRAN et al., 1991). Ou seja, à medida que o estudante-professor participa de estratégias que têm por objetivo 
posicioná-lo crítica e criativamente diante de diferentes situações de ensino e aprendizagem, ele passa a transitar por sua base de conhecimentos e a buscar conhecimentos que construiu previamente e que lhe dão condições de analisar a situação com o olhar de um professor em formação. (GIMENO SACRISTÁN, 1995; GRABER, 1995).

As experiências pedagógicas dessa natureza, principalmente aquelas do início da formação, necessitam ser desenvolvidas com atenção pelos professores-formadores, para que encaminhem a construção do conhecimento pedagógico do conteúdo dos estudantes-professores de maneira natural e gradativa, sem expô-los a situações que potencializem seus medos e a insegurança tradicionais para os iniciantes na docência. (GIMENO SACRISTÁN, 1995; GRABER, 1995; NASCIMENTO et al., 2009).

Com o passar do tempo e a desmistificação dessas atividades, espera-se que os estudantesprofessores se envolvam com as atividades acadêmicas e passem a interpretar esses momentos como intrínsecos à formação inicial e com grande potencial para qualificar sua formação docente e profissional.

Essa mudança de comportamento, o aumento da consciência sobre a própria formação e a ampliação e consolidação dos conhecimentos na base de conhecimentos favorecem, em grande medida, a inserção dos estudantes-professores no contexto de formação inicial, e permitem que assimilem melhor o fato de terem que dar aulas nas próximas etapas de sua formação.

Se o contato do futuro professor com situações de ensino e aprendizagem fictícias, simuladas ou vividas por outros estudantesprofessores ou professores têm potencial para reestruturar os conhecimentos da sua base de conhecimentos, ainda mais incisivas nesse processo serão as práticas pedagógicas em que ele próprio assumir o papel de professorestudante. (COCHRAN et al., 1991; FORMOSINHO, 2001; MARCON et al., 2007).

Nesses casos, os dilemas e as situaçõesproblema do próprio contexto de ensino e aprendizagem irão impor ao estudante-professor a necessidade de intervir a partir dos conhecimentos disponíveis em sua base de conhecimentos, o que trará como consequência, após uma turbulência inicial, a ampliação e o fortalecimento tanto dos próprios conhecimentos que a integram quanto, e fundamentalmente, do conhecimento pedagógico do conteúdo. Essas são estratégias de formação docente que guardam maiores semelhanças com o contexto de atuação profissional, e que, por isso, são algumas das integrantes das práticas como componente curricular que têm sido indicadas para 0 desenvolvimento da base de conhecimentos para o ensino, do conhecimento pedagógico do conteúdo e da personalidade docente e profissional dos estudantesprofessores. (BEHETS; VERGAUWEN, 2006; COCHRAN et al., 1991; JENKINS; VEAL, 2002; PARK; OLIVER, 2008).

\section{Considerações finais}

$\mathrm{Na}$ análise de alguns dos condicionantes da estruturação da base de conhecimentos para o ensino, percebe-se a importância dos programas de formação inicial de professores considerarem a história de vida dos estudantes-professores e os conhecimentos construídos ao longo da infância e do período escolar, sejam eles relacionados à escola, à educação, aos professores, aos alunos ou à profissão docente; ou à Educação Física, ao ensino, à aprendizagem, às modalidades esportivas e seus aspectos físicos, técnicos e táticos ou de convívio em grupo, por exemplo. Essas são algumas das questões que, assim como tantas outras com as quais os estudantes convivem nos contextos familiar, escolar e social, estruturam o lastro da sua futura base de conhecimentos, e com a qual eles ingressam no ensino superior.

Uma vez no ensino superior, nomeadamente no programa de formação de professores de Educação Física, essa base inicial de conhecimentos passa a sofrer influência de inúmeros estímulos, como por exemplo, dos professores-formadores, dos colegas, da comunidade, dos estudos e pesquisas, das práticas esportivas, das práticas pedagógicas e das demais práticas como componente curricular.

A magnitude da participação das práticas esportivas nesse processo estará sujeita às concepções que os programas de formação, os professores-formadores e os estudantesprofessores têm a seu respeito. Ou seja, as práticas esportivas podem tanto contribuir para o desenvolvimento de diferentes conhecimentos dos estudantes-professores, fundamentalmente aqueles relacionados com o conteúdo, quanto 
reforçar concepções deturpadas construídas anteriormente. Além disso, e mesmo reconhecendo as práticas esportivas como importantes estratégias de formação, a inviabilidade de desenvolver satisfatoriamente as habilidades motoras dos estudantes-professores durante a formação inicial coloca em cheque a profundidade da sua participação na estruturação dos conhecimentos da base de conhecimentos e na construção do conhecimento pedagógico do conteúdo.

Em muitas das instâncias da formação inicial e, principalmente, durante as práticas pedagógicas e as práticas como componente curricular, os estudantes-professores se defrontarão com inúmeras encruzilhadas, impostas por dilemas e situações-problema de diferentes contextos de ensino e aprendizagem reais, simulados ou fictícios, que the exigirão que se posicione e que tome decisões. Seja analisando uma prática pedagógica ou ministrando-a, os estudantes-professores terão oportunidade de requisitar, administrar e empregar os conhecimentos de sua base de conhecimentos, o que implicará na construção de novos conhecimentos e/ou a reestruturação dos conhecimentos anteriores. As decisões metodológicas serão tomadas a partir dos conhecimentos que sejam relevantes, significativos e salientes na base de conhecimentos, os quais, frequentemente, não terão sido construídos somente no programa de formação inicial, mas também nas experiências de vida do estudante-professor.

Apesar de muitas dessas decisões trazerem consequências positivas para os alunos e para a própria prática pedagógica, elas não podem entrar em choque com as concepções estruturantes do programa de formação, não podem ser tomadas à revelia dos professoresformadores, ao bel-prazer dos estudantesprofessores ou como seu único recurso para o momento.

Essa postura por parte dos estudantesprofessores, somada ao desconhecimento de sua existência por parte dos professores-formadores, poderá acarretar a gradativa solidificação de alguns estereótipos na base de conhecimentos dos estudantes-professores que, por sua vez, poderão incidir no desenvolvimento do seu conhecimento pedagógico do conteúdo.
Dada sua relevância para a formação inicial de professores de Educação Física, o tema ora abordado necessita ser considerado pelos programas de formação ao receberem os novos estudantes e ao analisarem a estrutura inicial da sua base de conhecimentos para o ensino.

A partir desse posicionamento quanto à base de conhecimentos para o ensino dos estudantesprofessores, os programas de formação inicial e os professores-formadores poderão planejar e implementar estratégias que viabilizem sua interrelação com o conhecimento pedagógico do conteúdo, de modo a estimular o desenvolvimento de ambos e, fundamentalmente, a estruturação da personalidade docente e profissional dos futuros professores.

\section{Referências}

BEHETS, D.; VERGAUWEN, L. Learning to teach in the field. In: KIRK, D.; MacDONALD, D.; O' SULLIVAN, M. (Org.). Handbook of Physical Education. London: Sage, 2006. p. 407-424.

BRASIL. Conselho Nacional de

Educação/Câmara de Educação Superior (CNE/CES). Parecer 58, de 18 de fevereiro de 2004. Diário Oficial da União, Brasília, DF, 2004. Disponível em:

$<$ http://portal.mec.gov.br/cne/arquivos/pdf/2004/p ces058 04.pdf >. Acesso em: 19 ago. 2009.

BRASIL. Conselho Nacional de

Educação/Conselho de Educação Superior (CNE/CES). Resolução 7, de 31 de março de 2004. Diário Oficial da União, Brasília, DF, v. 1 , p. 18, 2004. Disponível em: $<$ http://portal.mec.gov.br/cne/arquivos/pdf/ces070 4edfisica.pdf>. Acesso em: 19 ago. 2009.

CALDERHEAD, J. The development of knowledge structures in learning to teach. In: CALDERHEAD, J. (Org.). Teachers' professional learning. London, Washington, D.C.: Falmer Press, 1988. p. 51-64.

CAPEL, S. Moving beyond Physical Education subject knowledge to develop knowledgeable teachers of the subject. Curriculum Journal, v. 18, n. 4, p. 493-507, 2007.

COCHRAN, K. F.; KING, R. A.; DERUITER, J. A. Pedagogical content knowledge: a tentative model for teacher preparation. Annual Meeting of the American Educational Research Association, Chicago, 1991.

COSTA, L. C.; NASCIMENTO, J. V. O "bom" professor de Educação Física: possibilidades para a competência profissional. Revista da 
Educação Física/UEM, Maringá, v. 20, n. 1, p. 17-24, 2009. Disponível em:

<http://www.periodicos.uem.br/ojs/index.php/Rev EducFis/article/view/3336/2409 >. Acesso em: 27 nov. 2009.

DARIDO, S. C. Teoria, prática e reflexão na formação profissional em Educação Física. Motriz. Revista da Educação Física, v. 1, n. 2, p. 124-128, dez., 1995.

DARIDO, S. C. A educação física na escola e o processo de formação dos não praticantes de atividade física. Rev. bras. Educ. Fís. Esp., São Paulo, v. 18, n. 1, p. 61-80, 2004. Disponível em: $<$ http://www.usp.br/eef/rbefe/v18n12004/v18p61.p df $>$. Acesso em: 21 set. 2009.

ENNIS, C. Knowledge and beliefs underlying curricular expertise. Quest, v. 46, n. 2, p. 164175, 1994.

FILGUEIRA, F. M.; SCHWARTZ, G. M. Torcida familiar: a complexidade das inter-relações na iniciação esportiva ao futebol. Revista Portuguesa de Ciências do Desporto, Porto, v. 7, n. 2, p. 245-253, 2007. Disponível em: $<$ http://www.scielo.oces.mctes.pt/scielo.php?pid= S1645-05232007000200013\&script=sci arttext $>$. Acesso em: 11 set. 2009.

FORMOSINHO, J. A formação prática dos professores: da prática docente na instituição de formação à prática pedagógica nas escolas.

Revista Portuguesa de Formação de Professores, v. 1, p. 37-54, 2001.

GARCIA, R. P. Para um ensino superior com qualidade. Revista Portuguesa de Ciências do Desporto, v. 1, n. 1, p. 33-43, 2001.

GIMENO SACRISTÁN, J. Consciência e ação sobre a prática como libertação profissional dos professores. In: NÓVOA, A. (Org.). Profissão professor. Porto: Porto, 1995. p. 63-92.

GRABER, K. C. The influence of teacher education programs on the beliefs of student teachers: general pedagogical knowledge, pedagogical content knowledge, and teacher education course work. Journal of Teaching in Physical Education, v. 14, n. 2, p. 157-178, Jan., 1995.

\section{GRACA, A. O conhecimento pedagógico do} conteúdo no ensino do basquetebol. 1997. 331 f. Tese (Doutoramento em Ciências do Desporto) - Faculdade de Desporto, Universidade do Porto, Porto, 1997.

GRAÇA, A. O conhecimento pedagógico do conteúdo: o entendimento entre a pedagogia e a matéria. In: GOMES, P. B.; GRAÇA, A. (Org.).
Educação Física e desporto na escola: novos desafios, diferentes soluções. Porto: FCDEF-UP, 2001. p. 107-120.

GROSSMAN, P.; WILSON, S.; SHULMAN, L. Teacher of substance: subject matter knowledge for teaching. In: REYNOLDS, M. (Org.).

Knowledge base for the beginning teacher. New York: Pergamon Press, 1989. p. 23-36.

JENKINS, J. M.; VEAL, M. L. Preservice teachers' PCK development during peer coaching. Journal of Teaching in Physical Education, v. 22, n. 1, p. 49-68, Oct., 2002.

LIMA, S. M.; REALI, A. M. O papel da formação básica na aprendizagem profissional da docência (aprende-se a ensinar no curso de formação básica?). In: MIZUKAMI, M. G.; REALI, A. M. (Org.). Formação de professores, práticas pedagógicas e escola. São Carlos: EdUFSCar, 2002. p. 217-236.

MACHADO, A. A.; GOMES, R. A.; BRANDÃO, M. R.; PRESOTO, D. Especialização esportiva precoce: análise da Psicologia do Esporte. Pulsar, Jundiaí, v. 1, n. 1, p. 1-13, 2009.

Disponível em:

$<$ http://www.esef.br/revista/index.php/pulsar/articl e/viewFile/2/3>. Acesso em: 11 set. 2009.

MARCON, D.; NASCIMENTO, J. V.; GRACA, A. A construção das competências pedagógicas através da prática como componente curricular na formação inicial em Educação Física. Revista Brasileira de Educação Física e Esporte, São Paulo, v. 21, n. 1, p. 11-25, 2007. Disponível em: $<$ http://www.revistasusp.sibi.usp.br/pdf/rbefe/v21n 1/v21n1a2.pdf $>$. Acesso em: 27 nov. 2009.

MIZUKAMI, M. G. Aprendizagem da docência: algumas contribuições de L. S. Shulman. Revista Educação, Santa Maria, v. 29, n. 2, p. 1-11, 2004. Disponível em:

$<$ http://coralx.ufsm.br/revce/revce/2004/02/a3.htm >. Acesso em: 17 ago. 2009.

NASCIMENTO, J. V.; RAMOS, V.; MARCON, D.; SAAD, M. A.; COLLET, C. Formação acadêmica e intervenção pedagógica nos esportes. Motriz. Revista da Educação Física, Rio Claro, v. 15, n. 2, p. 358-66, 2009. Disponível em: <http://cecemca.rc.unesp.br/ojs/index.php/motriz/ article/view/2251/2378>. Acesso em: $23 \mathrm{dez}$. 2009.

OLIVEIRA, R. M.; MIZUKAMI, M. G. "Na escola se aprende de tudo..." In: MIZUKAMI, M. G.; REALI, A. M. (Org.). Aprendizagem profissional da docência: saberes, contextos e práticas. São Carlos: EdUFCar, 2002. p. 229-256. 
PARK, S.; OLIVER, J. S. Revisiting the conceptualisation of pedagogical content knowledge (PCK): PCK as a conceptual tool to understand teachers as professionals. Research in Science Education, v. 38, p. 261-284, 2008.

PERDIGÃO, A. L. Concepções pessoais de futuros professores sobre os processos de aprendizagem e de ensino. In: REALI, A. M.; MIZUKAMI, M. G. (Org.). Formação de professores, práticas pedagógicas e escola. São Carlos: EdUFSCar, 2002. p. 265-294.

PIRES, G. D. L. O esporte e os meios de comunicação de massa. In: GRUNENNVALDT, J. T. (Org.). Educação física, esporte e sociedade: temas emergentes. São Cristóvão: DEF/UFS, 2007. p. 1-10.

REALI, A. M.; TANCREDI, R. M. Interação escola-família: concepções de professores e práticas pedagógicas. In: REALI, A. M.; MIZUKAMI, M. G. (Org.). Formação de professores, práticas pedagógicas e escola. São Carlos: EdUFSCar, 2002. p. 73-100.

ROSA, M. I. P.; RAMOS, T. A. Memórias e odores: experiências curriculares na formação docente. Revista Brasileira de Educação, v. 13, n. 39, p. 565-599, set./dez., 2008.

\section{SÁ, M. P. Transmissibilidade nos hábitos de} actividade física: um estudo em alunos do sexo masculino do $10^{\circ}$ ao $12^{\circ}$ ano de escolaridade. 2000. 89 f. Dissertação (Mestrado em Ciências do Desporto) - Faculdade de Desporto, Universidade do Porto, Porto, 2000. Disponível em: <http://hdl.handle.net/10216/9989>. Acesso em: 22 fev. 2010.

SEGALL, A. Revisiting pedagogical content knowledge: the pedagogy of content/the content of pedagogy. Teaching and Teacher Education, v. 20, n. 5, p. 489-504, July, 2004.

SHULMAN, L. S. Knowledge and teaching: foundations of the new reform. Harvard Educational Review, v. 57, n. 1, p. 1-27, 1987.

SIEDENTOP, D. Content knowledge for Physical Education. Journal of Teaching in Physical Education, v. 21, n. 4, p. 368-377, 2002.

SILVA, M. L. R. Aplicação dos saberes na sala de aula: desafios para o professor. Notandum, Porto, v. XI, n. 16, p. 46-52, 2008. Disponível em: $<$ http://www.hottopos.com/notand16/malu.pdf>. Acesso em: 11 set. 2009.

STEFANE, C. A.; MIZUKAMI, M. G. A formação inicial vista a partir do exercício profissional da docência: contribuições de professores de Educação Física. In: MIZUKAMI, M. G.; REALI, A.
M. (Org.). Formação de professores, práticas pedagógicas e escola. São Carlos: EdUFSCar, 2002. p. 237-264.

TANI, G. Vivências práticas no curso de graduação de Educação Física: necessidade, luxo ou perda de tempo? In: SIMPÓSIO DE PESQUISA EM EDUCAÇÃO FÍSICA, 6., 1995, Florianópolis. Anais... Florianópolis: UFSC, 1995. p. 17-31.

TARDIF, M.; RAYMOND, D. Saberes, tempo e aprendizagem do trabalho no magistério.

Educação \& Sociedade, Campinas, v. 21, n. 73, p. 209-244, 2000. Disponível em: http://www.scielo.br/pdf/\%0D/es/v21n73/4214.pdf . Acesso em: 11 set. 2009.

TINNING, R. Engaging Siedentopian perspectives on content knowledge for Physical Education. Journal of Teaching in Physical Education, v. 21, n. 4, p. 378-391, July, 2002.

VAGO, T. M. O "esporte na escola" e o "esporte da escola": da negociação radical para uma revelação de tensão permanente. Movimento, Porto Alegre, v. III, n. 5, p. 4-17, 1996. Disponível em:

$<$ http://www.seer.ufrgs.br/index.php/Movimento/ar ticle/view/2228/936>. Acesso em: 21 set. 2009.

ZANETTI, M. C.; LAVOURA, T. N.; MACHADO, A. A. Motivação no esporte infanto juvenil.

Revista Conexões, Campinas, v. 6, n. Especial, p. 444-453, 2008. Disponível em:

$<$ http://polaris.bc.unicamp.br/seer/fef/search.php? $\mathrm{op}=$ search\&query $=$ Zanetti\&limit=author $>$. Acesso em: 11 set. 2009.

Apoio Financeiro: Universidade de Caxias do Sul

Endereço:

Daniel Marcon

Curso de Educação Física - UCS

Rua Francisco Getúlio Vargas, 1130, Petrópolis

Caxias do Sul, RS, Brasil

95070-570

e-mail: dmarcon@ucs.br

Recebido em: 23 de fevereiro de 2010.

Aceito em: 4 de maio de 2010.

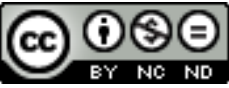

Motriz. Revista de Educação Física. UNESP, Rio Claro, SP, Brasil - elSSN: 1980-6574 - está licenciada sob Licença Creative Commons 